\title{
PRÁTICAS INOVADORAS EM EDUCAÇÃO POTENCIALIZADAS PELAS TECNOLOGIAS DIGITAIS
}

\section{INNOVATIVE PRACTICES IN EDUCATION ENHANCED BY DIGITAL TECHNOLOGIES \\ PRÁCTICAS INNOVADORAS EN EDUCACIÓN IMPULSADAS POR LAS TECNOLOGÍAS DIGITALES}

\section{Isabella Farias Batista* Maria Paulina de Assis**}

* Graduanda em História na Universidade Federal de Goiás (UFG). Catalão, Goiás, Brasil.

E-mail: isabellafariasb@gmail.com

** Doutora em Educação e Mestre em Comunicação e Semiótica pela Pontifícia Universidade Católica de São Paulo (PUC-SP). Psicóloga pela Universidade Federal de Uberlândia (UFU). Professora da UFG. Catalão, Goiás, Brasil. E-mail: paulina@ufg.br

Recebido para publicação em: 4.7.2018

Aprovado em: 21.5.2019

\section{Resumo}

Este artigo apresenta um grupo de nove soluções tecnológicas que se propõem a potencializar ações inovadoras de ensino. Essas soluções são brevemente descritas e analisadas sob critérios relacionados a características de inovação, conforme suas propostas (ensino híbrido, sala de aula invertida, gamificação e personalização do ensino). Propõe-se também uma fundamentação teórica para as abordagens inovadoras, baseadas em autores reconhecidos na área da Educação, enfocando o papel da mediação como característica essencial do educador em suas práticas docentes.

Palavras-chave: Inovação. Tecnologias. Mediação. Facilitador. Ensino.

\section{Abstract}

This article presents a group of nine technological solutions aiming at enhancing innovative teaching actions. These solutions are briefly described and analyzed under criteria related to innovation characteristics, according to their proposals (hybrid teaching, flipped classroom, teaching gamification and customization). It also proposes a theoretical basis for innovative approaches, based on recognized authors in the area of Education, focusing on the mediation role as an essential characteristic of the educator in his/her teaching practices.

Keywords: Innovation. Technologies. Mediation. Facilitator. Teaching. 


\section{Resumen}

Este artículo presenta un grupo de nueve soluciones tecnológicas que se proponen potenciar acciones innovadoras de enseñanza. Estas soluciones son brevemente descritas y analizadas según criterios relacionados con las características de innovación, de acuerdo con sus propuestas (enseñanza híbrida, salón de clase invertido, gamificación y personalización de la enseñanza). Se propone también una fundamentación teórica para los enfoques innovadores, basados en autores reconocidos en el área de la Educación, enfocándose en el papel de la mediación como característica esencial del educador en sus prácticas docentes.

Palabras clave: Innovación. Tecnologías. Mediación. Facilitador. Enseñanza.

\section{Introdução}

Em relatório divulgado pela Organização para Cooperação e Desenvolvimento Econômico (OCDE), Education at a Glance (EaG) (OECD, 2017), reafirmam-se as persistentes contradições do ensino no Brasil. Com dados de 45 países, o documento oferece informações dos sistemas educacionais com o objetivo de possibilitar um quadro comparativo entre as nações. De acordo com o estudo da OCDE, o Brasil ampliou os investimentos públicos em educação nos últimos anos e, com isso, coloca-se próximo da média dos países da organização. No entanto, esse aumento, além de não ter sido revertido na melhoria do desempenho dos alunos, foi destinado, em grande parte, para o ensino superior, em detrimento do ensino básico.

De acordo com os dados disponibilizados, em 2016, pelo Programa Internacional de Avaliação de Estudantes (Pisa), quase metade dos estudantes brasileiros (44,1\%) está abaixo do nível de aprendizagem considerado adequado. As avaliações do Pisa acontecem a cada três anos e abrangem três áreas do conhecimento - Leitura, Matemática e Ciências - e são aplicadas de forma amostral a estudantes matriculados a partir do $8^{\circ}$ ano do ensino fundamental na faixa etária dos 15 anos. Esses estudantes obtiveram uma pontuação que os coloca abaixo do nível 2 , considerado o mínimo para que o aluno se mostre capaz de exercer cidadania.

Diante desse cenário, todo esforço em busca de melhoras no ensino é louvável, e a tecnologia tem se mostrado uma ferramenta importante ao tornar possível a aplicação, de forma ampla e estruturada, de metodologias mais eficientes para o processo de aprendizagem.

Para o artigo, foram pesquisadas nove plataformas que propõem inovar o processo de ensino-aprendizagem ao permitirem o desenvolvimento de práticas pedagógicas que colocam o aluno no centro do processo, enriquecendo as atividades com estratégias didáticas diferenciadas.

As iniciativas descritas propõem a utilização de tecnologias digitais. Entretanto, é imprescindível observar que a tecnologia não dá conta de todos os aspectos da motivação e engajamento dos alunos nas atividades de aprendizagem. Sendo 
assim, é necessária uma postura diferenciada do professor em suas interações com os alunos e o uso de fundamentação teórica sólida como suporte às ações educativas.

As soluções tecnológicas descritas propõem viabilizar e/ou potencializar a aplicação de métodos ou estratégias didáticas - ensino híbrido (blended learning), sala de aula invertida (flipped classroom), personalização e "gameficação" (gamification) - que têm mostrado resultados e perspectivas animadoras de impacto nos ambientes tradicionais de ensino.

\section{Ambientes educacionais inovadores}

Presentes nos mais diversos ambientes e contextos, as tecnologias digitais também adentram os ambientes escolares. Elas podem proporcionar um imenso leque de recursos didáticos, possibilitando inserir a oportunidade de atender às diferenças individuais e às múltiplas facetas da aprendizagem (BITTENCOURT; ALBINO, 2017).

A internet pode ser uma ferramenta importante para a construção de uma sociedade do conhecimento inclusiva e democrática, que permita o acesso universal à informação e à liberdade de expressão. Por meio dela, a inovação percorre os mais variados caminhos e atinge campos diversos, inclusive o educacional (GETSCHKO, 2007).

Práticas inovadoras são elementos essenciais para o desenvolvimento econômico, social e educacional (ASSIS, 2011). Bates, Manuel e Oppenheim (2007) argumentam que, para ser bem-sucedida, a inovação deve ser tomada pela comunidade com um ajustamento aos métodos e/ou práticas de trabalho esperados. Mota (2011) destaca ainda que, de uma forma ampla, ela deve conseguir atender às demandas sociais ao se associar à aplicação do conhecimento. De acordo com Johnson (2010), a inovação pode ser gerada mais facilmente em ambientes colaborativos em que há abertura para o compartilhamento de ideias, que são recombinadas, formando as novas e boas ideias.

A inovação

pode ser gerada

mais facilmente

em ambientes

colaborativos

Dessa forma, os ambientes educacionais têm potencial para propiciar a colaboração para a inovação. Nesses locais, deve-se assumir o compromisso com a inovação na busca contínua das melhores maneiras de planejar e reinventar o ambiente de ensino e aprendizagem, tendo por base uma educação pautada na experiência e a educação como transformadora das pessoas e da sociedade, como propõe Dewey (DEWEY; CUNHA, 2007).

Além disso, o cenário educacional é considerado um campo social que visa ao desenvolvimento dos indivíduos e, com isso, a busca por inovação pode ser entendida também como intervenções que ocorrem em nível local tanto por iniciativa de estudantes, educadores e escolas quanto por comunidades. A partir de tais práticas e ações, é possível visualizar a produção de novos "significados, respostas e hipóteses em relação aos desafios do presente" (CAVALLO et al., 2016, p. 145). 
Dessa forma, apresentam-se aqui algumas abordagens metodológicas que podem servir como inspiração para inovações na sala de aula. São elas: ensino híbrido, sala de aula invertida, personalização e "gameficação", descritas a seguir.

Ensino Híbrido. Tem se consolidado como uma das tendências para a educação do século 21. Trata-se de uma abordagem que mescla momentos de estudo de conteúdos e instruções usando recursos on-line, e outros em que o ensino ocorre em uma sala de aula, com a possibilidade de interação entre os alunos e estes com o professor (STAKER; HORN, 2012).

Nessa forma de ensino, o conteúdo e as instruções devem ser elaborados especifıcamente para a disciplina ministrada. Além disso, de acordo com Valente (2014), as etapas presenciais devem contar necessariamente com supervisão do professor, complementando o que foi desenvolvido on-line e, assim, proporcionando um processo de ensino e de aprendizagem mais eficiente, interessante e personalizado.

Para falar em ensino híbrido, deve-se partir do pressuposto de que existem diferentes maneiras de aprender e de ensinar. Logo, essa abordagem precisa ser pensada no âmbito de modelos curriculares que propõem mudanças e mudem o foco da educação, privilegiando a aprendizagem ativa dos alunos - individualmente e em grupo (BACICH; MORAN, 2015). Moran (2015) chama atenção para o fato de que a educação sempre foi, em sua essência, híbrida, uma vez que sempre combinou vários espaços, tempos, atividades, metodologias e públicos. A singularidade do momento atual está na ampliação dessas possibilidades por meio da tecnologia, devido à sua capacidade de integrar espaços e tempo. O ensinar e aprender passa a acontecer em uma interligação profunda entre os chamados mundo físico e mundo digital. Essa interação se configura em uma sala de aula ampliada, que se mescla constantemente, capaz de abrir a escola para o mundo e trazer o mundo para dentro da escola, dado que com a internet e a divulgação aberta se pode aprender em qualquer lugar, a qualquer hora e com inúmeras pessoas diferentes (ALMEIDA; VALENTE, 2012). Independentemente do caminho a ser trilhado para essas transformações, é fundamental que se repense o foco do modelo pedagógico a ser implantado, a postura que o professor assume diante do aluno e qual o tipo de interação entre o estudante e o objeto de estudo.

Sala de aula invertida. Pode ser também considerada como um subtipo de ensino híbrido. Trata-se de uma modalidade para a qual o conteúdo e as instruções são estudados on-line antes de o aluno frequentar a sala de aula. A função da sala de aula é drasticamente alterada, porque se transforma em um local dinâmico, propício à realização de atividades práticas e discussões em grupo (VALENTE, 2014). No ensino tradicional, a sala de aula serve para o professor transmitir informação para o aluno, que deve estudar o que foi difundido, assumindo, muitas vezes, uma postura passiva diante do processo de aprendizado. Por outro lado, na abordagem da sala de aula invertida, insta-se uma postura mais ativa, o professor trabalha de acordo com as dificuldades e as demandas de aprendizagem dos alunos (EDUCAUSE LEARNING INITIATIVE, 2012). 
As mais bem-sucedidas salas de aula invertidas, segundo o relatório Flipped Classroom Field Guide (2016), compartilham três características principais: 1) os ambientes de aprendizagem em classe são altamente estruturados (muitas vezes, planejados minuto a minuto); 2) as atividades em sala de aula envolvem uma quantidade significativa de questionamento, resolução de problemas e de outras atividades de aprendizagem ativa, obrigando o aluno a recuperar, aplicar e ampliar o material aprendido on-line; 3) os estudantes são fortemente incentivados, por meio de rankings das atividades da classe e das expectativas dos instrutores, a completar o trabalho fora da aula e a participar de reuniões presenciais.

Diante dessa necessidade quanto ao uso consciente, planejado e direcionado da tecnologia no universo educacional, Bacich e Moran (2015) propõem que se ofereça aos estudantes possibilidades de interação com o fenômeno antes do estudo teórico, como forma de aprimorar o modelo da sala de aula invertida. Ou seja, que eles sejam incentivados a desenvolver atividades que envolvam a descoberta e a experimentação.

Valente (2014) ainda ressalta que o tipo de material e as atividades que o aluno realiza on-line e na sala de aula devem variar de acordo com a proposta a ser implantada, de modo a criar diferentes possibilidades para essa abordagem pedagógica. Além disso, como ressaltado por Moran (2015), é importante que os projetos desenvolvidos estejam ligados à vida dos alunos, às suas motivações, e que o professor saiba gerenciar todas as etapas, envolvendo-os e motivando-os. Os alunos devem se sentir protagonistas de uma aprendizagem rica e estimulante.

Personalização. O ritmo e a maneira de aprendizagem diferem de aluno para aluno, e isso vem sendo observado e estudado por pesquisadores da educação com o intuito de aprimorar o sistema de ensino-aprendizagem. Em estudos desenvolvidos na primeira metade do século 20, Vygotsky já chamava a atenção para tais diferenças quanto às formas de desenvolvimento (OLIVEIRA, 1995).

É importante

que os projetos

desenvolvidos

estejam ligados à

vida dos alunos

Na concepção de Vygotsky, existem duas categorias para níveis de desenvolvimento: o real e o potencial. Para ele, o nível de desenvolvimento real da criança caracteriza o desenvolvimento de forma retrospectiva, isto é, refere-se a etapas já alcançadas, já conquistadas pela criança, as funções psicológicas nessa categoria são resultados de processos de desenvolvimento já completados. Por outro lado, o nível de desenvolvimento potencial está relacionado à capacidade da criança de desempenhar tarefas com a ajuda de adultos ou companheiros mais capazes, ou seja, existem tarefas que ela não é capaz de realizar sozinha, mas que se torna capaz de realizar se receber instruções, pistas ou assistência (OLIVEIRA, 1995). Um ponto crucial dessas relações propostas está na compreensão de que os níveis de desenvolvimento nessas duas categorias são únicos para cada indivíduo. 
A personalização vai ao encontro da necessidade de articulação das dimensões social e individual, das mudanças na escola e nos sistemas educacionais. Valente (2018) utiliza o termo "aprendizagem personalizada", em vez de personalização do ensino. Segundo o autor, nesse tipo de abordagem o aluno está envolvido na criação de atividades de aprendizagem adaptadas às suas preferências, aos seus interesses pessoais e à curiosidade (VALENTE, 2018, p. 33)

Para a implantação da aprendizagem personalizada para grandes grupos de alunos, as tecnologias têm um papel fundamental. O uso de softwares que viabilizem essa metodologia de ensino deve alterar a forma como os professores gerem a sala de aula.

Diante desse cenário, a sobrecarga de tarefas, a exaustão, o isolamento e a pressão pelo imediatismo - condições comumente impostas aos professores - são armadilhas que dificultam a mudança e o real avanço das práticas educacionais. Em relação a esses profissionais, Messina (2013) propõe três ações centrais: que eles expressem e escutem a si mesmos; que realizem a reflexão na ação (na, sobre e para a ação) e que desenvolvam uma mentalidade para assumir riscos. Essa postura implica combinar o tempo de trabalho em grupo com o tempo de trabalho individual e a reafırmação do compromisso com a reflexão.

"Gameficação". O lúdico utilizado como metodologia no ensino e na aprendizagem pode auxiliar o desenvolvimento da criança. Além de favorecer a aprendizagem, permite que sejam desenvolvidas a criatividade e a autonomia. Apesar das ricas possibilidades, ainda se observa a resistência de alguns educadores quanto à sua inserção nas práticas docentes (MARQUES, 2012).

Para alguns, o lúdico se resume a jogos, e para outros, a brincadeiras. No entanto, seu significado é, atualmente, muito mais abrangente. Almeida (2009) destaca que apesar de o lúdico ter sua origem na palavra latina ludus, que quer dizer jogo, passou a ser reconhecido como traço essencial de psicofisiologia do comportamento humano. Ou seja, não se refere apenas ao jogar, ao brincar e ao movimento espontâneo: suas implicações extrapolaram esse conceito inicial. Abrange as brincadeiras e os jogos, mas acima disso faz parte do desenvolvimento humano (MARQUES, 2012). Macedo, Petty e Pessoa (2005) enfatizam a importância da afetividade na aprendizagem, fator essencial para a motivação, que pode ser possibilitado pelos aspectos lúdicos dos jogos no ensino e que pode atuar como aspecto motivacional para os alunos.

Vygotsky destacou em seus estudos a relevância das brincadeiras infantis enquanto função pedagógica, uma vez que são atividades que favorecem o envolvimento dos alunos (OLIVEIRA, 1995). Dentro desse novo universo de possibilidades didáticas emergentes e das novas tecnologias na sociedade da informação, os jogos digitais destacam-se. Eles se caracterizam como recursos pedagógicos que propiciam o multiletramento dos alunos e exigem do professor um novo fazer pedagógico (COELHO et al., 2016). Além disso, Mattar (2013) ressalta que a mo- 
tivação para um envolvimento intenso, necessário ao processo de aprendizado, é satisfatoriamente atingido pelos games.

Para Ferreira (2009), viver ludicamente é uma forma de intervenção no mundo, significa ser parte de um conhecimento prático e de um protagonismo ativo. Infelizmente, como afirma Marques (2012), em algumas escolas, o lúdico se restringe às aulas de Educação Física e aos momentos de recreação, não sendo, portanto, explorado de forma adequada, nem utilizado quando se observam necessidades educacionais específicas.

Na busca por uma educação de qualidade, capaz de promover a inclu-

sucesso do uso do lúdico

nas práticas

pedagógicas

está intimamente

relacionado

à aptidão do

professor são, o lúdico aparece como um modo de promover o desenvolvimento de capacidades e facilitar a formação de valores e de conhecimentos. Portanto, não pode ser visto como meio de divertimento ou tratado como estratégia simples de motivação ou incentivo nas aulas aplicadas. Pelo contrário, deve se fazer presente nos projetos escolares de maneira ampla, flexível, aprofundada e bem-estruturada (MARQUES, 2012).

De igual modo, ainda de acordo com Marques (2012), o sucesso do uso do lúdico nas práticas pedagógicas está intimamente relacionado à aptidão do professor, em como ele faz uso dessa metodologia. 0 educador deve ser capaz de separar as variadas formas de brincadeiras, como os jogos, as histórias, as dramatizações, as danças, de acordo com o conteúdo e as metas que queira atingir.

\section{Exemplos de ambientes baseados em tecnologias digitais que podem ser inovadores para a educação}

A seguir, apresenta-se o resultado de um levantamento sobre organizações que oferecem soluções em tecnologia educacional para as metodologias analisadas e a análise comparativa entre essas iniciativas.

Educare. Portal de aulas particulares que tem como objetivo a entrega de um conteúdo mais personalizado e um ensino mais eficaz, é uma plataforma on-line de aulas particulares e tutoria continuada no Brasil (https://www.educarebr.com.br).

EvoBooks. Empresa de educação que se propõe, dentro da cultura digital, a preparar e instrumentalizar os diferentes agentes envolvidos nos processos pedagógicos para uma troca de conhecimentos mais rica, envolvente e inspiradora. Tem os princípios pedagógicos de valorização da aprendizagem significativa e ativa, integrada a uma sólida metodologia educativa; atividades digitais como complemento ao desenvolvimento do currículo da escola; e programa pautado na implementação de atividades para uso em sala de aula por meio de sequências didáticas (https://www. programainspira.com.br).

Geekie. Plataforma adaptativa que ajuda o aluno a estudar de acordo com suas necessidades. Mediante uma prova dentro da ferramenta, o aluno descobre o que 
estudar. A partir daí, tem acesso a aulas e exercícios sobre o tema. Além disso, possibilita aos professores e à escola o acompanhamento do desempenho de cada estudante, da classe, da série e de toda a instituição (http://www.geekie.com.br/).

Guten. Empresa de educação e tecnologia que oferece uma plataforma de leitura com objetivo de transformar estudantes em leitores proficientes e engajados. Alia interface, conteúdos prazerosos e didática para engajar os estudantes na leitura, ao mesmo tempo em que permite o acompanhamento contínuo (https://gutennews. com.br/).

Joy Street. Empresa que concebe, desenvolve e opera plataformas digitais de aprendizagem, as quais fomentam o engajamento de alunos e professores por intermédio de jogos. Oferece soluções em tecnologias educacionais lúdicas para criação de cenários de aprendizagem baseados no diálogo e na diversão (https:// www.joystreet.com.br).

Knewton Brasil. Plataforma digital que faz uso das tecnologias de análise e processamento de dados em volume massivo com o objetivo de oferecer a estudantes e professores a possibilidade de um ensino focado nas fragilidades individuais de cada aluno. Assim, os estudantes têm acesso a ferramentas de aprendizado customizadas e os professores a possibilidade de preparar melhor as aulas, encontrando conteúdos mais adequados para as turmas, além da opção de acompanhar mais atentamente o desempenho de cada aluno (https://www.knewton.com).

Mind Lab. Organização especializada em sistemas de aprendizagem para o desenvolvimento de tecnologias educacionais inovadoras, de abordagem interacionista, que atuam na capacidade da pessoa de se modificar e aprender novas habilidades. Promove o desenvolvimento de habilidades de raciocínio e para a vida. O coração da Metodologia Mind Lab é a noção de que a maneira mais eficaz de aprender é por meio de uma experiência imediata e autêntica. O jogo é o exemplo perfeito de tal experiência - é divertido, envolvente e emocionante, portanto, estimula o envolvimento (https://www.mindlab.com.br).

QMágico. Empresa que visa o desenvolvimento de software para soluções tecnológicas educacionais que possibilitem o atendimento personalizado das demandas de aprendizagem dos alunos. Oferece ferramentas que auxiliam professores e gestores a acompanhar o aprendizado de seus alunos por meio dos objetos digitais disponibilizados (https://www.qmagico.com.br).

Zoom. Empresa que desenvolve e implementa soluções que transformem a sala de aula em um ambiente no qual os alunos se sintam instigados a realizar montagens, observar, comparar, refletir, levantar hipóteses, pesquisar, argumentar, registrar. Tem por soluções educacionais inovadoras os conjuntos Lego ${ }^{\circledR}$ Education, material didático, plataformas digitais e suporte técnico-pedagógico (https://www. zoom.education). 
Quadro 1 - Análise comparativa das soluções disponibilizadas

\begin{tabular}{|c|c|c|c|c|c|c|c|c|}
\hline & $\begin{array}{l}\text { Ensino } \\
\text { híbrido }\end{array}$ & $\begin{array}{l}\text { Sala } \\
\text { de aula } \\
\text { invertida }\end{array}$ & Personalização & Lúdico & $\begin{array}{l}\text { Foco no } \\
\text { professor }\end{array}$ & $\begin{array}{l}\text { Foco } \\
\text { no } \\
\text { aluno } \\
\end{array}$ & $\begin{array}{l}\text { Fornece } \\
\text { conteúdo }\end{array}$ & $\begin{array}{l}\text { Fornece } \\
\text { métodos }\end{array}$ \\
\hline Educare & & & $x$ & & & $x$ & $x$ & \\
\hline EvoBooks & $x$ & $x$ & & & $x$ & $x$ & $x$ & $x$ \\
\hline Geekie & & & $x$ & & & $x$ & $x$ & \\
\hline Guten & $x$ & X & $x$ & & $x$ & $x$ & X & X \\
\hline Joy Street & $x$ & & $x$ & $x$ & & $x$ & $x$ & X \\
\hline Knewton & $x$ & $x$ & $x$ & & $x$ & $x$ & & $x$ \\
\hline Mind Lab & $x$ & & & $x$ & & $x$ & $x$ & $x$ \\
\hline QMágico & $x$ & $x$ & $x$ & & $x$ & $x$ & & $x$ \\
\hline Zoom & $x$ & & X & X & & $x$ & X & X \\
\hline
\end{tabular}

Fonte: Elaborado pelas autoras.

Um ponto em comum em todas as iniciativas citadas está relacionado ao direcionamento do ensino: o foco no aluno. O estudante é tratado como protagonista do processo de aprendizagem e, ainda quando elas se dirigem aos professores, essas tecnologias incentivam uma postura alternativa aos sistemas de educação tradicionais, demandando que os docentes atuem como facilitadores, mediadores, gestores do processo educativo.

A predominância de soluções que se baseiam na proposta do blended learning pode estar relacionada à grande variedade de modelos e aplicações para essa abordagem.

Ademais, com relação às soluções que objetivam a viabilização do ensino personalizado: elas surgem e se multiplicam devido à possibilidade atual de processamento de dados em velocidade e volume nunca alcançados. Essas iniciativas refletem a necessidade de compreender de maneira individual as demandas de aprendizagem.

Além disso, cabe destacar que, apesar de também oferecerem alternativas que se configuram como games, as iniciativas que trabalham com as possibilidades de ensino por meio da ludicidade não se restringem a eles, pelo contrário, conversam com as variadas formas do lúdico e atingem diversas faixas etárias.

\section{0 professor como facilitador - essencial para a implementação de práticas inovadoras em educação}

A inovação vem assumindo a tarefa de solucionar problemas educacionais estruturais e complexos, em contraponto às propostas conservadoras, que desconsideram a diversidade dos contextos sociais e culturais (MESSINA, 2013). Como proposto por Cysneiros (1998), a inovação e as tecnologias da informação na educação podem se configurar como mecanismos para regular social e pedagogicamente o aluno. 
No entanto, a inovação não pode ser encarada como um fim em si mesma, mas como um meio para transformar os sistemas educacionais. Deve possibilitar que os sujeitos e as instituições sejam mais donos de si, mais plenos e autônomos em sua maneira de ser, fazer e pensar (MESSINA, 2013). Daí a importância de se pensar na postura do professor, de suas crenças sobre educação e de seu preparo para atuar como professor inovador.

Existem vários termos que tentam explicar ou conceituar esse novo papel do professor - o de facilitador -, exigido pelas mudanças tecnológicas na sociedade contemporânea. Cabe, no entanto, retomar uma das concepções vygotskianas sobre o funcionamento psicológico da aprendizagem: a mediação. Em termos genéricos, trata-se do processo de intervenção de um elemento intermediário em uma relação; o ato se torna complexo, a relação deixa de ser direta e passa a ser mediada por esse elemento (OLIVEIRA, 1995). Essa mesma autora destaca a visão de Vygotsky sobre a compreensão do professor como mediador, como elemento intermediário do processo de aprendizado, ponte entre o conhecimento já consolidado e as etapas posteriores, ainda não alcançadas. Ou seja, o professor tem o papel explícito de provocar avanços que não ocorreriam espontaneamente pelo aluno. Vygotsky propõe uma intervenção pedagógica que tenha como objetivo trabalhar com a importância do meio cultural e das relações entre indivíduos, explicitando a ideia de reconstrução e reelaboração por parte do indivíduo dos significados que Ihe são transmitidos.

Moran (2015) propõe o papel do professor como curador, cuidador e orientador. Curador ao escolher o que é relevante entre a enorme quantidade de informações disponíveis e ajudar os alunos a encontrar sentido mosaico de materiais e atividades disponíveis. Cuidador ao apoiar, acolher, estimular, valorizar, orientar e inspirar os estudantes. E, por fim, deve ser competente para orientar as classes, os grupos e cada aluno.

Porém, essa nova configuração impõe que esses profissionais sejam bem-preparados, bem-remunerados, valorizados, o que ainda corresponde a uma realidade distante da maioria das instituições educacionais no Brasil.

\section{Considerações finais}

Partindo de uma reflexão acerca da situação crítica da educação brasileira no cenário atual, o artigo propõe alternativas de apoio à prática docente, mostrando um rol de opções inovadoras que poderão auxiliar os educadores em suas práticas profissionais. 0 artigo trouxe uma mostra de nove opções de soluções em tecnologia educacional. Destaca-se que as propostas baseadas em tecnologia têm potencial para enriquecer o ensino inovador e esse, por sua vez, necessita de professores com competências para atuarem como facilitadores da aprendizagem de seus alunos. 
Uma abordagem da teoria de mediação vygotskiana é proposta como fundamento para as ações inovadoras de ensino, que servem como suporte ao uso das tecnologias descritas. O professor é o mediador das ações de ensino e aprendizagem, e embora tenha à sua disposição as mais espetaculares tecnologias, é na interação entre educadores e educandos, ou seja, no seio das relações interpessoais, que a aprendizagem é propiciada, com a internalização dos conhecimentos - processo inter e intrapsíquico.

Acredita-se que este trabalho poderá contribuir com professores, designers educacionais, pesquisadores e outros profissionais relacionados à docência que estejam preocupados com inovações em sala de aula - essencialmente aquelas que não sejam apenas novidades, e sim que possuam suporte de teorias educacionais consolidadas, contribuindo, assim, para a qualidade da educação no país.

\section{Referências}

ALMEIDA, Anne. Recreação: ludicidade como instrumento pedagógico. [S. I.]: Cooperativa do Fitness, 23 jan. 2009. Disponível em: https://www.cdof.com.br/ recrea22.htm. Acesso em: 21 out. 2017.

ALMEIDA, Maria Elizabeth Bianconcini de; VALENTE, José Armando. Integração currículo e tecnologias e a produção de narrativas digitais. Currículo sem

Fronteiras, [S. I.], v. 12, n. 3, p. 57-82, 2012.

ASSIS, Maria Paulina de. Learning design: conceitos, métodos e ferramentas.

2011. Tese (Doutorado em Educação) - Pontifícia Universidade Católica de São Paulo, São Paulo, 2011.

BACICH, Lilian; MORAN, José Manuel. Aprender e ensinar com foco na educação híbrida. Revista Pátio, Porto Alegre, v. 17, n. 25, p. 45-47, 2015.

BATES, Melanie; MANUEL, Sue; OPPENHEIM, Charles. Models of early adoption of ICT innovations in higher education. Ariadne, [S. I.], n. 50, 2007.

BITTENCOURT, Priscilla Aparecida Santana; ALBINO, João Pedro. Cultura digital e as tecnologias de informação e comunicação nas escolas brasileiras. Tecnologia Educacional, Rio de Janeiro, v. 216, p. 42-50, 2017.

CAVALLO, David et al. Inovação e criatividade na educação básica: dos conceitos ao ecossistema. Revista Brasileira de Informática na Educação, [S. I.], v. 24, n. 2 , p. 143-161, 2016. 
COELHO, Patrícia Margarida Farias et al. Ensino e jogos digitais: uma breve análise do game "produção de textos: trabalhando com pontuação" como recurso didático. Tecnologia Educacional, Rio de Janeiro, p. 7-19, ago. 2016. Número especial.

CYSNEIROS, Paulo Gileno. Novas tecnologias na sala de aula: melhoria do ensino ou inovação conservadora. Informática Educativa, [S. I.], v. 12, n. 1, p. 11-24, 1998.

DEWEY, John.; CUNHA, Marcus Vinicius da. Democracia e educação: capítulos essenciais. São Paulo: Ática, 2007.

EDUCAUSE LEARNING INITIATIVE. 7 Things you should know about flipped classrooms. [S. I.], Feb. 2012. Disponível em: http://net.educause.edu/ir/library/ pdf/eli7081.pdf. Acesso em: 10 out. 2017.

FERREIRA, L. A importância do lúdico na Educação Infantil. Artigonal, [S. I.], set. 2009. Disponível em: http://www.artigonal.com/educacao-infantil-artigos/aimportancia-doludico-na-educacao-infantil-1230873.html. Acesso em: 21 out. 2017.

FLIPPED classroom field guide. [S. I.: s. n., 2016]. Disponível em: https://tlc.uic.edu/ files/2016/02/Flipped-Classroom-Field-Guide.pdf. Acesso em: 24 maio 2016.

GETSCHKO, Demi. Participação e presença na rede: pesquisa sobre o uso das tecnologias da informação e da comunicação no Brasil: TIC Domicílio e TIC Empresas 2006. São Paulo: Comitê Gestor da Internet no Brasil, 2007.

GOMES, P. Ensino híbrido é o único jeito de transformar a educação. São Paulo: Porvir, 20 fev. 2014. Disponível em: http://porvir.org/ensino-hibrido-e-unico-jeito-detransformar-educacao/. Acesso em: 9 out. 2017.

JOHNSON, Steven. Where good ideas come from: the natural history of innovation. New York: Riverhead Books, 2010.

MACEDO, L.; PETTY, A. L. S.; PESSOA, N. C. Os jogos e o lúdico na aprendizagem escolar. Porto Alegre: Artmed, 2005.

MARQUES, Cláudia Luíza. A metodologia do lúdico na melhoria da aprendizagem na educação inclusiva. Revista Eixo, Brasília, DF, v. 1, n. 2, p. 80-91, 2012.

MATTAR, João. Games em educação: como os nativos digitais aprendem. 2. ed. São Paulo: Pearson Prentice Hall, 2010. 
MESSINA, Graciela. Mudança e inovação educacional: notas para reflexão. Cadernos de Pesquisa, São Paulo, n. 114, p. 225-233, 2013.

MORAN, José. Mudando a educação com metodologias ativas. In: SOUZA, Carlos Alberto de; MORALES, Ofelia Elisa Torres (org.). Convergências midiáticas, educação e cidadania: aproximações jovens. Ponta Grossa: UEPG/PROEX, 2015. E-book (p. 15-33).

MOTA, Ronaldo. O papel da inovação na sociedade e na educação. Desafios da gestão universitária contemporânea. Porto Alegre: Artmed, 2011. p. 81-96.

OECD. Education at a glance 2017: OECD indicators. Paris: OECD Publishing, 2017. Disponível em: https://www.oecd-ilibrary.org/education/education-at-aglance-2017_eag-2017-en. Acesso em: 24 maio 2019.

OECD. PISA 2015 results: excellence and equity in education, volume 1. Paris: OECD Publishing, 2016. Disponível em: http://dx.doi.org/10.1787/9789264266490en. Acesso em: 11 out. 2017.

OLIVEIRA, Marta Kohl. Vygotsky: aprendizado e desenvolvimento um processo sócio histórico. São Paulo: Scipione, 1995.

SHARMA, Pete; BARRETT, Barney. Blended learning: using technology in and beyond the language classroom. Oxford: Macmillan, 2011.

STAKER, H.; HORN, M. B. Classifying K-12 blended learning. Mountain View: Innosight Institute, 2012. Disponivel em: http://www.christenseninstitute.org/wpcontent/uploads/2013/04/Classifying-K-12-blended-learning.pdf. Acesso em: 9 out. 2017.

VALENTE, José Armando. Blended learning e as mudanças no ensino superior: a proposta da sala de aula invertida. Educar em Revista, Curitiba, p. 79-97, 2014. Número especial, n. 4

VALENTE, José Armando. A sala de aula invertida e a possibilidade do ensino personalizado: uma experiência com a graduação em midialogia. In: $\mathrm{BAClCH}$, Lilian; MORAN, José Manuel (org.). Metodologias ativas para uma educação inovadora: uma abordagem teórico-prática. Porto Alegre: Penso, 2018. p. 26-44. 